\title{
SINTAXIS DEL DISCURSO HABLADO Y RECREACIÓN DE LA ORALIDAD EN EL DIÁLOGO PLATÓNICO**
}

\author{
Rodrigo VERANO \\ Universidad Autónoma de Madrid (España)
}

\section{RESUMEN}

Este artículo aborda el estudio de una serie de fenómenos sintácticos presentes en la lengua de los diálogos platónicos y los relaciona con la imitación de la lengua hablada que Platón lleva a cabo en estas obras. Partiendo de los trabajos que se han llevado a cabo en lenguas modernas y sin menospreciar la rica tradición de estudios de estilística platónica, se aíslan y analizan fenómenos tales como anacolutos, construcciones paratácticas, elipsis, figuras parentéticas, repeticiones y enumeraciones, que en esta propuesta son reinterpretados como manifestaciones de inmediatez comunicativa introducidas conscientemente por el autor con el propósito de dar mayor verosimilitud a su recreación de la conversación humana.

PAlabras ClaVE: Platón, diálogo platónico, diálogo literario, oralidad, estilística, lingüistica griega.

\section{AbSTRACT}

This paper studies a number of syntactic phenomena in the dialogues of Plato, and explains them as being related to the imitation of the spoken language to be found in these works. Based both on research carried out on modern languages and on an important tradition of studies approaching the stylistics of Plato's language, it focuses on instances such as anacoluthon, parataxis, ellipsis, parenthesis, repetition and cumulation, here interpreted as features of spoken syntax consciously placed in the text by the author for a more achieved imitated orality.

KeYwords: Plato, Platonic dialogue, literary dialogue, orality, stylistics, Greek linguistics.

* Este trabajo forma parte del proyecto de investigación FFI 2015-65541. Agradezco a los informantes anónimos de la revista Oralia las valiosas sugerencias y correcciones que han contribuido notablemente a mejorar la versión inicial. 


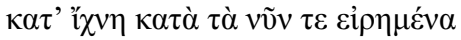

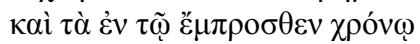

(Pl. Phaedo, 115b-c)

\section{Los diálogos de Platón y la lengua gRiega Hablada}

La obra de Platón ha suscitado a lo largo de la historia una discusión de tales dimensiones que no es posible encontrar una metáfora que ayude a expresar la cantidad y variedad de las interpretaciones surgidas al hilo de las páginas de sus diálogos, o que permita dar una idea de lo extraordinario de su repercusión. Desde la propia inauguración de la institución académica hasta las corrientes hermenéuticas contemporáneas, Platón y su legado han sido transformados en un problema filosófico -o, más bien, una multitud de ellos-, de manera que puede afirmarse, sin temor a la exageración, que sobre la obra del filósofo de Atenas ha sido dicho prácticamente todo.

En este entramado de voces discordantes que buscan hacerse con la clave de bóveda del pensamiento que se manifiesta y, al mismo tiempo, se oculta tras las conversaciones de los personajes de sus diálogos, una idea es compartida con unanimidad excepcional por, si no la totalidad, al menos una vasta mayoría de sus lectores y críticos: que el tono general de la lengua que encontramos en sus páginas refleja con extraordinaria perfección el de las conversaciones cotidianas entre personas cultas que posiblemente inspiraron su composición: una percepción que lleva implícita la invitación a considerar los diálogos platónicos una fuente privilegiada para el estudio de la lengua griega antigua hablada en la medida en que los rasgos propios de esta se manifiestan en las líneas de aquellos ${ }^{1}$.

Delimitar, sin embargo, el valor y significado de esa medida es una tarea que tropieza con problemas de partida que no pueden ser ignorados sin comprometer los posibles resultados del estudio: en primer lugar, el hecho -no por evidente menos relevante- de que los diálogos de Platón no son en ningún caso transcripciones, sino composiciones literarias y, por tanto,

${ }^{1}$ Así lo expresa, en un estudio fundamental sobre estilística platónica que será objeto de atención en las páginas siguientes, $\mathrm{H}$. Thesleff, al referirse al estilo que él denomina «coloquial» («colloquial style») y que considera predominante en los diálogos: «Plato on the whole employs the style of cultivated every-day conversations; this can be regarded as reasonably evident a priori» (Thesleff 1967: 63-64). Puede citarse una gran cantidad de pasajes de crítica literaria en este sentido. Sirva como ilustración esta observación extraída de una fuente tan canónica como The Cambridge History of Classical Literature: «Plato's skill with language was admired by ancients as well as by moderns. He could write in a manner which has the appearance or the illusion of everyday educated speech, using an unpretentious vocabulary, numerous particles, and realistic anacolutha» (Easterling y Knox 1985: 495). 
aunque su autor haya tenido la intención de llevar a cabo una auténtica mímesis conversacional en sus obras -lo que no es sino una hipótesis-, o incluso postulando -algo mucho menos verosímil- que detrás de cada diálogo subyazca una conversación real imitada en las páginas escritas, es innegable que ha existido un proceso de textualización que es último responsable de la lengua que encontramos en ellos; y, en segundo lugar, el riesgo que entraña una aproximación a la obra completa de Platón como un todo monolítico en lo que a la realización lingüística se refiere, obviando la compleja y riquísima variedad estilística que hay en sus escritos y que afecta directamente a los rasgos de la lengua.

En realidad, ambos problemas pueden abordarse desde la tensión entre oralidad y escritura que es constitutiva del diálogo literario como género, el cual es concebido como una pieza escrita que reproduce, con mayor o menor interés y acierto, el habla conversacional. En términos del modelo desarrollado por Koch y Oesterreicher (2007), quienes abogan por un entendimiento de lo oral y lo escrito desde un punto de vista concepcional -relativo no a la realización física de un acto comunicativo, sino a la realidad lingüística que se genera en ese acto-, como un continuum que se extiende progresivamente desde un extremo que acoge la formulación arquetípicamente oral (inmediatez) hasta otro en el que se sitúa la expresión más marcadamente escrita (distancia), podría decirse que, en el diálogo platónico, a la presencia de determinados fenómenos propios de la inmediatez comunicativa a que invita la verosimilitud artística se opone la aparición más que esporádica de elementos de lengua elaborada que posibilita la producción escrita, cuya impronta se deja así sentir también en el crisol estilístico platónico ${ }^{2}$.

El objetivo de estudiar la recreación de esta fenomenología propia de la lengua hablada en un diálogo literario de Platón obliga, por tanto, a afrontar ambos escollos. Respecto al primero de ellos, partiendo -en un ejercicio de honestidad científica- del hecho de que, por razones evidentes, la lengua que hablaron Sócrates y sus contemporáneos nos será para

${ }^{2}$ No es posible, por razones de espacio, profundizar aquí en los fundamentos teóricos de la lingüística de variedades alemana, cuyas contribuciones han sido decisivas en el estudio de las relaciones entre oralidad y escritura en las lenguas romances y son el punto de partida de la propuesta que se desarrolla aquí. El texto básico es el de Koch y Oesterreicher (1990), citado aquí en su edición española (Koch y Oesterreicher 2007), que introduce modificaciones y ampliaciones sobre la original: su segundo capítulo contiene una introducción a los conceptos básicos de teoría (véase también López Serena 2006 para una contextualización en la historiografía lingüística reciente). El modelo de análisis ha sido empleado con anterioridad en estudios sobre recreación literaria de la lengua hablada (López Serena 2007; Del Rey Quesada 2015) y, particularmente, como aproximación al diálogo platónico (Verano 2017a y, especialmente, 2017b). 
siempre desconocida, y el grado de éxito de la mímesis platónica nunca podrá establecerse con objetividad y precisión, se impone una metodología que permita identificar determinados elementos discursivos en el texto que constituyan, al menos plausiblemente, rasgos o marcas de inmediatez comunicativa. Estos elementos, ya que no por comparación con otro tipo de material lingüístico, pueden intentar aislarse con auxilio de los resultados obtenidos para el análisis de las características de la lengua hablada en otras lenguas, cuyo estudio continuado ha proporcionado, en las últimas décadas, un conjunto cada vez mayor y más ajustado de rasgos típicos del discurso inmediato de naturaleza universal ${ }^{3}$.

Queda aún un segundo escollo, referido a la diversidad estilística de la obra platónica y a la confluencia en ella de variedades discursivas diferentes, no siempre explicables desde el contexto comunicativo coloquial o conversacional que da coherencia interna al diálogo. En auxilio de este segundo problema vienen los estudios clásicos sobre la lengua de Platón y, en particular, los de H. Thesleff, quien, desde un enfoque lingüístico y literario, fue pionero en abordar de una forma sistemática la cuestión de la multiplicidad de estilos que coexisten -no pocas veces, además, en diversos grados de simultaneidad- en el diálogo platónico y aislar con extraordinaria sensibilidad las características propias de cada uno de ellos ${ }^{4}$. El análisis de Thesleff (1967) permite diseccionar cada uno de los diálogos en diferentes partes de acuerdo con las coordenadas estilísticas que son predominantes en cada momento, y constituye así una útil herramienta para afrontar

\footnotetext{
${ }^{3}$ Cfr. el capítulo cuarto de la monografía de Koch y Oesterreicher (2007: 70-184). El carácter universal de estos rasgos será objeto de discusión más adelante $(\S 4)$.

${ }^{4}$ Debido a su instrumentalización en el problema de la cronología de los diálogos, la lengua y el estilo de Platón han sido objeto de uno de los estudios más minuciosos de cuantos existen en filología griega. La llamada estilometría platónica ha querido ver en las pequeñas variaciones lingüísticas constatables en los diferentes diálogos síntomas de su pertenencia a distintas etapas de la producción del filósofo, y contribuir así al espinoso tema de su datación. La obra inaugural de esta línea que se remonta al siglo xix es la de Campbell (1867), a la que siguieron los trabajos de Dittenberger (1881) y Ritter (1888); todas estas contribuciones perfilaron un método que obtuvo un impulso definitivo en la monografía de Lutoslawski (1896), y que ha continuado dando frutos hasta bien entrado el siglo xx (cfr. Díaz Tejera 1961). Los que se citan son únicamente hitos fundamentales de una bibliografía inabarcable por su profusión y complejidad: para el estado actual de la cuestión y una visión histórica, las mejores aproximaciones son las de Thesleff (1982: 2-7 y el conspectus en 8 y ss.) y Brandwood (1990). La única obra que se ocupa, sin embargo, de la estilística platónica per se -y no como un mera herramienta para afinar la datación de los diálogos-, en un estudio sistemático llevado a cabo sobre la totalidad del corpus platónico es la de Thesleff (1967), quien, a partir de una serie escogida de fenómenos lingüístico-literarios que consideró marcadores estilísticos, propuso diez variedades o estilos presentes en el corpus de Platón y distinguió cuáles de ellos se identifican o predominan -incluyendo su posible coexistencia y transición- en cada uno de los pasajes que forman cada una de las obras del filósofo (cfr. §2).
} 
la variedad discursiva, lo que a su vez posibilita la sección de partes concretas del corpus platónico y su uso como subcorpus específico para un tipo de estudio particular.

Aunando las aportaciones anteriormente expuestas, el objetivo del presente estudio es encontrar en los diálogos platónicos los fenómenos lingüísticos cuya presencia se explica mejor desde las condiciones de oralidad propias de la situación comunicativa representada en la ficción literaria. La metodología empleada para ello se servirá, de un lado, de las contribuciones de la lingüística de variedades y sus conclusiones a partir del estudio de la lengua hablada tanto en su realización natural como en su recreación literaria; y, de otro, de los logros de un estudio centenario sobre la lengua de los diálogos de Platón, que ha dado como resultado una de las caracterizaciones estilísticas más completas que existen sobre una producción literaria.

Los principios básicos de esta caracterización, que servirán también de introducción a las variedades lingüísticas presentes en la obra del filósofo, serán objeto de discusión en el epígrafe siguiente (\$2) y servirán para aislar un corpus compuesto únicamente por pasajes continentes de variedades estilísticas más próximas a la oralidad en su dimensión concepcional. Algunos apuntes metodológicos sobre esta consideración de la oralidad se recogen en $(\S 3)$. Desde esta perspectiva $(\S 4)$ se llevará a cabo el estudio de -una parte de- la fenomenología que puede considerarse representativa de la sintaxis de la inmediatez comunicativa y, consiguientemente, de la oralidad, que asiste a las páginas del Fedón, diálogo que ha conservado para la posteridad las últimas horas de vida de Sócrates, y una de las piezas maestras de la literatura de la Antigüedad.

Se trata, en todo caso, de una primera propuesta, basada en una única obra que deberá ser revisada y afinada con posterioridad, con miras a completarse y corregirse no únicamente con el resto de la producción platónica sino también con cualquier otra obra literaria o documentación escrita en griego antiguo en que puedan detectarse las huellas de la oralidad.

\section{APROXIMACIÓN ESTILÍSTICA AL DiÁlOgO PLATÓNICO: LOS ESTUdIOS} DE H. THESLEFF

\subsection{Los diez estilos platónicos}

Tras un análisis pormenorizado del corpus al completo, Thesleff (1967) postuló la existencia de diez clases estilísticas genéricas que comparecen reiteradamente en los diálogos de Platón: (1) estilo coloquial; (2) estilo conversacional semi-literario; (3) estilo retórico; (4) estilo patético; 
(5) estilo intelectual; (6) estilo narrativo del mito; (7) estilo histórico; (8) estilo ceremonial; (9) estilo legal; (10) estilo "onkos» ${ }^{5}$.

El hecho de presentar los diez estilos en una lista numerada puede crear la falsa impresión de que todos se dan en igualdad de proporciones; en realidad, si atendemos a las obras consideradas propias de la madurez literaria platónica (i. e. República, Banquete, Fedón o Gorgias), los estilos (6) a (10) se dan en pasajes excepcionales o bien muy localizados en el discurso -como en el caso de las narraciones míticas del número (6) o las proclamaciones ceremoniales de (8)-. El estilo histórico es poco frecuente y figura en la lista únicamente «for the sake of comparison and completeness» (Thesleff 1967: 75). Por último, el estilo propio de la tradición jurídica y legal, fácilmente reconocible, encuentra su máxima manifestación en Las Leyes, e igualmente tardío es el auge, como ha sido ya mencionado, del estilo «onkos».

El núcleo estilístico de la conversación que constituye el diálogo platónico se forma por combinación de los números (1) a (5), sobre la base de los tipos (1) y (3), que se corresponden, respectivamente, con el estilo coloquial o conversacional neutro, por así decir, y el estilo retórico que caracteriza ciertas intervenciones más elaboradas, del que son buena muestra los discursos eróticos del Banquete. Entre ambos, a modo de compromiso, el estilo conversacional semiliterario -(2) - es propio de aquellos pasajes en los que no se detectan -o, dicho de otra manera, se evitan- los rasgos coloquiales del estilo (1), sin documentarse tampoco el artificio propio de (3). Por tanto, de este análisis puede concluirse que la mayor parte del diálogo platónico se desarrolla lingüísticamente en una variedad de estilos que oscila entre un polo coloquial o conversacional («cultivated every-day conversation») y un polo retórico, con una amplia gama de situaciones intermedias. Sobre esta base, los estilos patético -(4) - e intelectual -(5)- son definidos por Thesleff como un conjunto de matices accesorios que se superponen a los estilos anteriores y, al actuar sobre ellos, logran efectos que pueden constituir una caracterización específica. En el caso del llamado estilo patético, esta etiqueta se refiere a la afectación discursiva que pueden manifestar en ciertos contextos tanto el estilo (1) como el (3). Con la calificación de intelectual se hace referencia a una preferencia por la expresión abstracta y la argumentación pura que va haciendo aparición en el

${ }^{5}$ En sus denominaciones originales: «(1) colloquial style; (2) semi-literary conversational style; (3) rhetorical style; (4) pathetic style; (5) intellectual style; (6) mythic narrative style; (7) historical style; (8) ceremonious style; (9) legal style; (10) onkos style» (Thesleff 1967: 63). El último término - onkos- hace referencia al sustantivo griego ǒ $\gamma \kappa \varsigma$, que denota normalmente la masa o materia de los cuerpos y, en el ámbito de la retórica, se emplea para calificar un estilo hinchado o incluso bombástico: «grave», «expansivo» o «elevado» podrían ser traducciones adecuadas. 
coloquio o en las intervenciones retóricas de los diálogos desde la etapa más temprana y que va ganando cada vez más peso en la configuración del discurso platónico.

La delimitación de estos tipos se lleva a cabo mediante la localización de una serie de marcadores estilísticos que se agrupan en constelaciones, de manera que la presencia de un rasgo aislado no es significativa, pero su aparición en compañía de otros sí puede resultar determinante a la hora de identificar el estilo que predomina en un pasaje del texto. Estos rasgos o marcadores estilísticos se adscriben a todo tipo de fenomenología lingüística: desde la fonética y la morfología (asonancias, elusión del hiato, crasis, frecuencia de palabras compuestas, uso de diminutivos, etc.) hasta la sintaxis (subordinaciones, empleo de participios, anacolutos, asíndeton, etc.), el orden de palabras y otros indicadores pragmático-textuales (posición del adjetivo, hipérbaton, sístrofe, transiciones, etc.), la semántica y el léxico (se incluye una lista de palabras cuya mera aparición puede considerarse un marcador estilístico), además de numerosos factores de orden retórico y literario (pleonasmo, lítotes, etc.) ${ }^{6}$.

\subsection{El estilo coloquial y su caracterización}

La delimitación del estilo coloquial o conversacional de Thesleff descansa sobre los principios de la estilística europea de la primera mitad del siglo xx, cuyas ideas se dejan sentir en la descripción de fenómenos característicamente orales que el autor lleva a cabo:

It is customary to refer to certain general trends which would seem to be characteristic of language at all periods, namely (a) exaggeration: hyperbole, abundance, emphasis, strenghtening, etc.; (b) understatement: irony, attenuation, approximation, etc.; (c) lively and pictureque forms of expression: imagery, quotations, proverbs, puns, etc.; (d) brevity and disorganization of expression: ellipse, anacoluthon, parataxis, etc.; and (e) mechanization: idioms, set phrases, etc. (Thesleff 1967: 74)

A partir de estos principios, la lista de marcadores estilísticos comprende, de un lado, una serie de construcciones morfosintácticas y fenómenos pragmático-discursivos considerados prototípicos de la lengua coloquial y, de otro, una serie de elementos léxicos que también parecen situarse en esta variedad discursiva. Entre los primeros se cuentan los anacolutos, elipsis y pleonasmos; las expresiones de comparación aproximativa (por ejem$80-94)$.

${ }^{6}$ La lista completa de los marcadores estilísticos puede encontrarse en Thesleff (1967: 
plo, las introducidas por $\mu \tilde{\alpha} \lambda \lambda$ ov 'más bien'); la recurrencia de los dativos commodi e incommodi y del dativo ético, sobre todo de pronombres personales; la tendencia a la parataxis y a la oración simple; el empleo de diminutivos y superlativos (especialmente de adverbios); la aparición ocasional -y a menudo inconsistente- del presente histórico; la irrupción de un orden de palabras expresivo y «enfático» (cfr. Thesleff 1967: 85, n. 4); la presencia generalizada de crasis en sintagmas específicos ${ }^{7}$; la frecuencia de elementos idiomáticos y proverbios, así como imágenes y juegos de palabras, no pocas veces con efecto cómico y burlesco.

Junto a estos fenómenos y construcciones, se lista una serie de palabras y expresiones cuya presencia ayuda a contextualizar estilísticamente determinados pasajes y a identificarlos como coloquiales. Entre ellas hay elementos que apuntan directamente a la situación comunicativa -conversacional- en alguno de sus aspectos (deícticos, referencias al interlocutor, etc.):

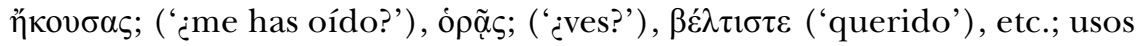
de partículas que parecen estar asociados al discurso oral ( $\kappa \alpha i ́$ copulativo en narraciones, кaíto adversativo, etc.); otros marcadores discursivos que inciden sobre la propia formulación ( $\delta \tilde{\eta} \lambda \mathrm{ov}$ ő $\tau$, $\pi \mathrm{ov}$, etc.); interjecciones (iov́); giros y expresiones más o menos fosilizadas (cỉ ßov́ $\lambda \varepsilon 1$ ); además de una serie de palabras -o significados específicos de ciertas palabras- que el autor vincula con el estilo coloquial ${ }^{8}$.

7 Quizá el único rasgo de naturaleza fónica que puede hallarse en la lista.

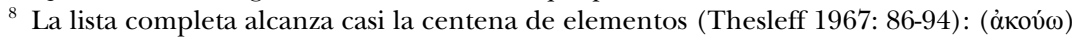

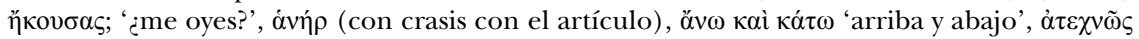

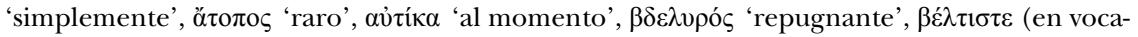

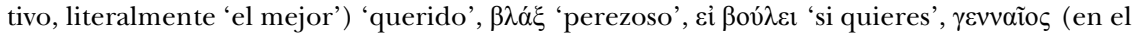

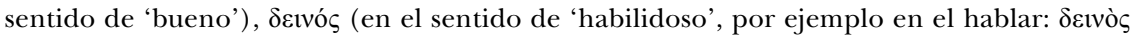

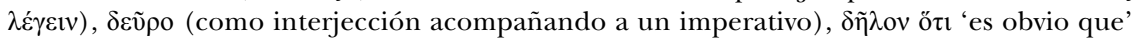

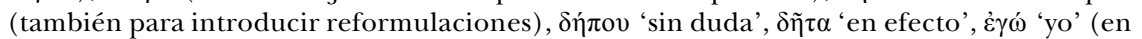

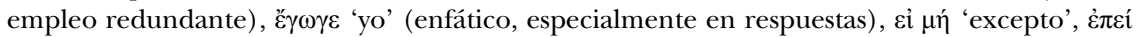

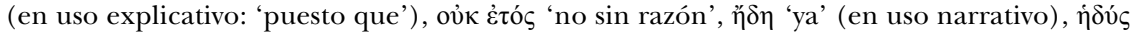

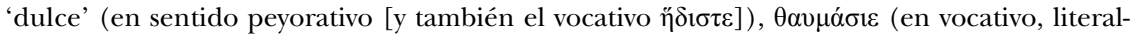

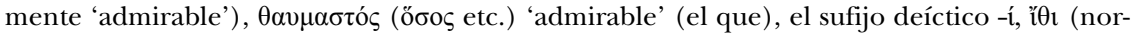

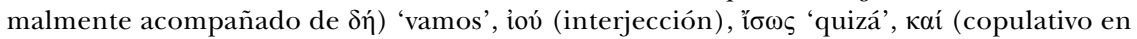

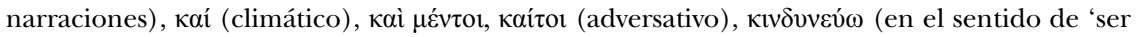

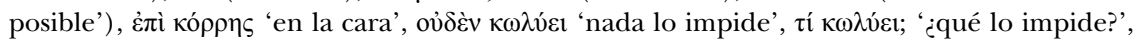

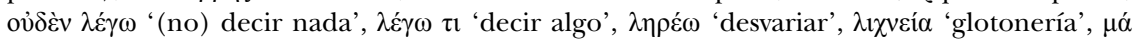

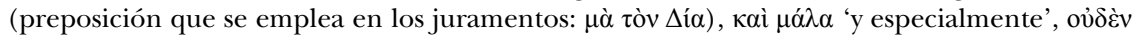

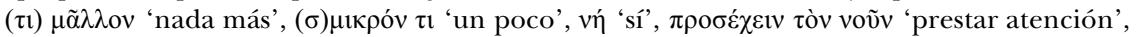
vข̀v $\delta \eta ́$ 'ahora mismo', ő $\delta \varepsilon$ (como pronombre personal), oĩos (en uso exclamativo), ó $\rho \tilde{\alpha} \varsigma$;

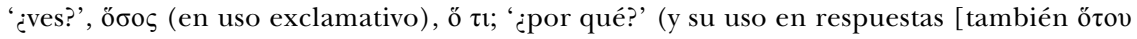

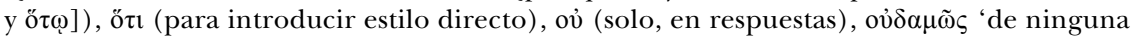

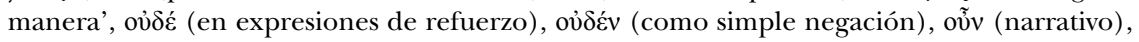

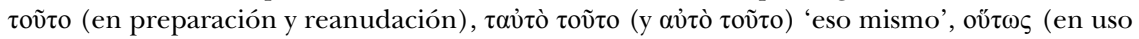

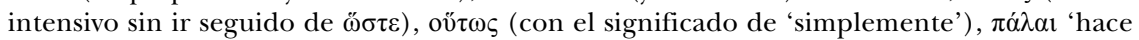




\section{FEDÓN, O SOBRE EL ALMA}

El diálogo sobre el que se centrará el análisis de las páginas que a continuación se suceden es el Fedón, una obra central del corpus platónico 9 . Clasificada tradicionalmente en la primera tetralogía por tratar un asunto relacionado con el proceso y la muerte de Sócrates, es indiscutiblemente una obra de madurez, tanto literaria como filosófica, que en ningún caso puede adscribirse a una época temprana de la producción del autor. El diálogo describe las últimas horas de vida del filósofo ateniense en compañía de algunos de sus amigos en la cárcel. Se trata de un diálogo de gran complejidad estructural, pues se abre con una parte dramática -la conversación entre Fedón y Equécrates-, que sirve a su vez de marco al relato de Fedón que constituye el núcleo de la obra, si bien la narración de este diálogo dentro del diálogo se ve de vez en cuando interrumpida por la intervención de los personajes de la escena marco, a menudo en momentos de gran intensidad.

Según el análisis de Thesleff (1967: 133-135), en el diálogo predominan el estilo coloquial -(1) - y el conversacional semiliterario -(2)-, a veces con tintes patéticos -(4) - o desarrollos abstractos de tipo intelectual -(5)-, además de la conocida narración mítica -(6)- dedicada a las postrimerías del alma. Precisamente esta última parte, de naturaleza narrativa, junto a otros pasajes en los que no se detecta ninguna huella de estilo coloquial, son los que han quedado excluidos del análisis que abarca, no obstante, la mayor parte de la obra ${ }^{10}$.

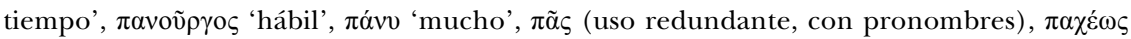

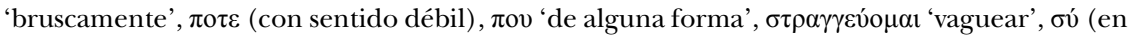

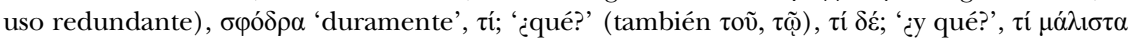

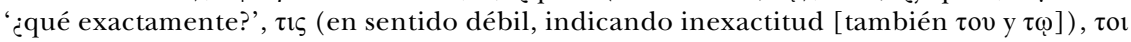

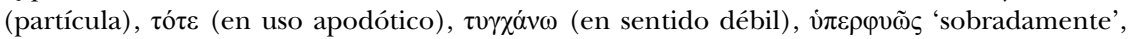

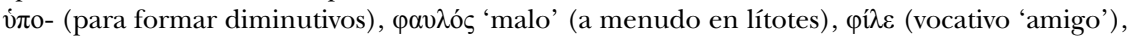

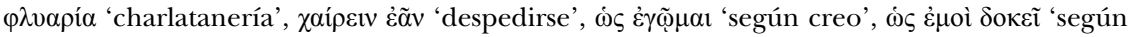
me parece a mí'.

${ }^{9}$ El texto empleado es el de la edición burnetiana (Burnet 1911) acompañado de un comentario que ha sido de gran utilidad en la dilucidación de muchos pasajes, entre ellos algunos que se citan aquí. Se han tenido también muy presentes las notas de Verdenius (1958) y Gallop (1975), además de las de Reinhard (1920), así como las traducciones inglesa de Long (Sedley y Long 2010) y las españolas de García Gual (1986) y de Ramos Jurado (2002). Todas las traducciones que se ofrecen son propias.

${ }^{10}$ Desde 107a hasta concluida la narración mítica en 115a (cfr. Thesleff 1967: 133-135). En general, existen trazos del estilo (1) en la mayor parte del diálogo. Una característica adicional del Fedón es que, por la clase de situación que tiene lugar en la ficción, la especial cercanía y familiaridad de los personajes que hablan y el alto contenido emocional, las partes e intervenciones más conversacionales han sido especialmente cuidadas y son más extensas que en otras obras del corpus. 


\section{INMEDIATEZ COMUNICATIVA Y DIÁLOGO LITERARIO: ACLARACIÓN METODOLÓGICA}

La minuciosidad y precisión de los análisis thesleffianos son tales que, medio siglo después de su aparición, permanecen imbatibles. Los avances que durante este medio siglo, sin embargo, ha experimentado la lingüística en su aproximación a la oralidad, invitan a una revisión de la cuestión de los estilos platónicos para complementar las conclusiones de Thesleff y ofrecer una nueva perspectiva al problema de la lengua de Platón. Así pues, el estudio de los distintos elementos que caracterizan la lengua hablada no debe llevarse a cabo desde la particularidad de cada uno de ellos sino, más bien, con Bustos Tovar, desde la idea de que, en su variedad, «dependen todos ellos de un rasgo capital que domina todo el proceso del diálogo conversacional: la ausencia de planificación discursiva determinada por la espontaneidad de la realización elocutiva y por la familiaridad pragmática entre los interlocutores» (2001: 197).

Esta espontaneidad y ausencia de planificación tiene que ver con el hecho de que las conversaciones humanas son procesos en los que, gracias a la cooperación mutua entre los participantes, la comunicación se va construyendo en relación con un contexto que puede variar de un instante a otro, y llevando a cabo revisiones constantes tanto sobre la propia formulación y como sobre el canal y la recepción por parte del destinatario. Todas estas vicisitudes pueden dejar -y dejan frecuentemente- gran cantidad de huellas y rastros en el discurso lingüístico, marcas de inmediatez comunicativa que apuntan a una realización típicamente oral y que son susceptibles de ser imitados por medio de un artificio literario.

A la necesidad de tener muy presente que a este artificio literario concurren únicamente rasgos selectos y siempre mediados por el proceso de textualización escritural se ha hecho ya alusión en la introducción a este trabajo. La descripción de fenómenos sintácticos propios de la inmediatez comunicativa que figura a continuación se ha llevado a cabo a partir de las orientaciones expuestas por Koch y Oesterreicher (2007), quienes proponen una serie de rasgos prototípicos de la oralidad ilustrados mediante intercambios conversacionales en las lenguas que constituyen su objeto de estudio, pero que, al menos desde cierto punto de vista, pueden considerarse universales, en tanto que responden a ciertas características inherentes a la inmediatez comunicativa, con independencia de su actualización idiomática (cfr. Koch y Oesterreicher 2007: 71).

Al mismo tiempo, han sido también inspiración y fuente metodológica para este estudio las contribuciones sobre la lengua española coloquial y su imitación en la literatura de López Serena (2007), quien, desde la misma perspectiva teórica, encara un problema de naturaleza similar al que se 
aborda aquí. Con estas herramientas, el análisis que se llevará a cabo en las páginas siguientes se centrará en los fenómenos de tipo sintáctico, aunando estos rasgos universales de la inmediatez comunicativa con otras contribuciones sobre la sintaxis de la lengua hablada y su recreación literaria. No se atenderá, por su escasa relevancia en la imitación platónica de la oralidad, la fenomenología de tipo fónico ${ }^{11}$ o morfológico ${ }^{12}$. Por el contrario, las cuestiones léxico-semánticas ${ }^{13} \mathrm{y}$, sobre todo, pragmático-textuales ${ }^{14}$ sobre-

${ }^{11}$ El contexto de familiaridad característico de las situaciones a las que se asocia prototípicamente la inmediatez comunicativa puede verse reflejado en determinados fenómenos fonéticos. Más allá de la posibilidad de que existan realizaciones diversas de un mismo fonema en variación diafásica, la pronunciación inmediata puede plasmarse en una articulación relajada o puede verse alterada la velocidad del habla. Koch y Oesterreicher recurren al lenguaje musical y hablan de formas «allegro e incluso presto, articuladas con menor esmero, en las que parte de los significantes sonoros se contraen o atrofian» (2007: 177). Es posible evocar estos rasgos fonéticos a través de la escritura mediante grafías idiosincrásicas, pero esta voluntad de representación en ningún caso se da en Platón. El único pasaje que puede aducirse in extremis de todo el Fedón -y se trata de una instancia asimismo excepcional considerando el corpus platónico en su conjunto- es el que se recoge en el siguiente ejemplo, en referencia a la caracterización dialectal de uno de los personajes, Cebes:

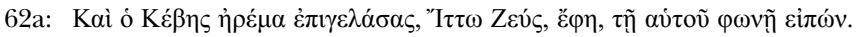
$Y$ Cebes, con una sonrisa leve, dijo, en su propia lengua: "Que lo sepa Zeus».

La forma î $\tau \omega$, con articulación en $-\tau \tau$ - en lugar de î $\tau \tau \omega$, que es la correspondiente ática para la tercera persona del imperativo de perfecto activo de oĩ $\delta \alpha-{ }^{*}(\mathrm{~F}) \hat{i} \delta-\tau \omega-$, revela la procedencia beocia del hablante. Naturalmente, se trata de un rasgo dialectal, y no de la representación gráfica de una pronunciación específicamente relacionada con la inmediatez comunicativa; pero es quizá lo más lejos a lo que puede llegar Platón en lo que se refiere a peculiaridades fónicas en sus escritos.

12 Tampoco las investigaciones llevadas a cabo sobre lenguas modernas han arrojado tendencias de carácter universal en este campo lingüístico. Cfr. Koch y Oesterreicher (2007: 182184) sobre la dificultad de delimitar universales morfológicos de inmediatez comunicativa y las posibles líneas de trabajo al respecto. Competerá a trabajos futuros, basados quizá en corpus nueva y más sólidamente establecidos de textos griegos representativos de la inmediatez comunicativa encontrar variantes morfológicas específicas o características.

${ }^{13}$ Respecto a la selección léxica, los contextos de cercanía entre interlocutores que caracterizan las situaciones en que se da la comunicación inmediata acogen una serie de voces características, que se convierten en ocasiones en auténticas «palabras testigo» que comparecen -como es el caso de las recogidas por Thesleff (1967) citadas en la nota 8 de este trabajoúnica o preferentemente en este tipo de discurso. Desde el punto de vista semántico, entran en juego dos valores troncales cuya presencia articula toda una serie de estrategias subsidiarias: la afectividad y la expresividad (Koch y Oesterreicher 2007: 166 ss.). Estas estrategias, enfocadas a lograr efectos de énfasis y contundencia (Koch y Oesterreicher 2007: 168) necesitan ser abordadas en un nuevo estudio que sepa entroncar, a su vez, con contribuciones clásicas como las de Tarrant (1946; 1948; 1951) o el propio Thesleff (1954, entre otras).

${ }_{14}$ No solamente en lo que respecta a las llamadas partículas y a su posible vinculación a la inmediatez comunicativa, un campo de trabajo que, pese a los muchos e importantes avances que se han llevado a cabo en las últimas décadas en la descripción de estos elementos, 
pasan por su volumen las posibilidades de este trabajo y deberán ser atendidas separadamente. Vale la pena recordar que no se trata de un estudio exhaustivo ni agota en modo alguno las posibilidades que este enfoque puede tener en el diálogo platónico y en general en la literatura griega antigua; antes bien, quiere ser un primer paso que arroje alguna luz sobre estas posibilidades.

\section{La SINTAXIS DE LA LENGUA HABLADA EN EL FEDÓN}

La sintaxis es quizá uno de los ámbitos en que más marcadamente difieren las variedades lingüísticas de la inmediatez y la distancia comunicativas. El menor nivel de planificación constitutivo del discurso inmediato se traduce en una sintaxis tendente a la aposición de elementos más o menos independientes, y evita las construcciones demasiado largas y complejas que desafían los límites de la memoria discursiva y requieren un esfuerzo por parte de hablante y oyente que va en contra del principio comunicativo de economía lingüística. De ello no debe inferirse en modo alguno que la sintaxis de la lengua oral sea una versión desviada o incorrecta de la sintaxis prototípica de la lengua escrita, una idea que entroncaría con el sesgo escriptista con que la tradición gramatical ha llevado a cabo la descripción de las lenguas ${ }^{15}$. Además de las interferencias que el carácter espontáneo del discurso hablado pueda provocar en determinadas construcciones, la lengua oral cuenta con sus propias estructuras sintácticas, quizá no en forma de periodos interminables, pero sí complejas en otros sentidos, y que cumplen eficientemente su propósito en el discurso.

\subsection{Incidencia de la ausencia de planificación en la sintaxis}

La naturaleza de la producción discursiva oral, que es siempre un proceso en curso de desarrollo, deja en algunas ocasiones huellas en la formulación en forma de desajustes diversos respecto a las reglas de construcción sintáctica. Estos puntos de desencuentro entre la sintaxis gramatical de una lengua y su actualización discursiva, denominados habitualmente anacolutos, incluyen gran variedad de fenómenos -las faltas de concordancia, las interferencias entre construcciones principales y subordinadas, las pro-

permanece aún escasamente explorado (cfr. Duhoux 1997). También en cuanto a la rica fenomenología discursiva de orden pragmático-textual que se manifiesta en el diálogo platónico y que debe estudiarse desde estos presupuestos.

${ }^{15}$ Cfr. López Serena (2008) para una visión crítica de este enfoque y su trascendencia en la descripción lingüística y en la consideración de la lengua hablada. 
lepsis, las oraciones interrumpidas, etc.- que se explican bien desde los contextos de formulación oral y están por tanto asociados prototípicamente al dominio de la inmediatez comunicativa.

Desde este punto de vista, es posible analizar la presencia de este tipo de fenómenos en el diálogo literario como una marca estilística, introducida conscientemente con objeto de caracterizar la intervención de un personaje y emular su espontaneidad enunciativa ${ }^{16}$. Pasajes de esta índole, como ilustra el siguiente ejemplo, no son infrecuentes en el diálogo platónico:

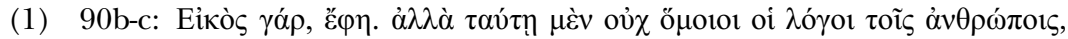

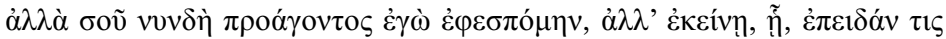

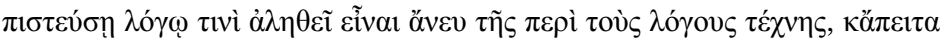

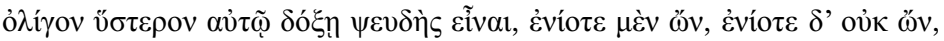

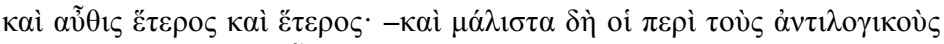

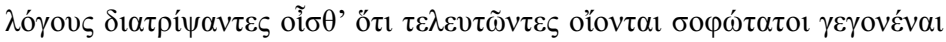

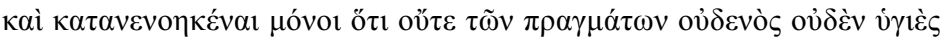

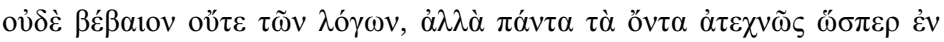

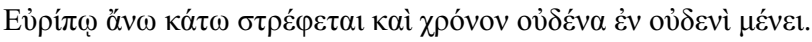

Probable, efectivamente-dijo-. Pero no es en eso en lo que se parecen los argumentos a los hombres -lo que yo estaba haciendo ahora, más bien, era seguir tus pasos-, sino en esto: en que, cuando uno confía en que un argumento es verdadero, sin conocer el arte de la argumentación, y luego poco después le parece que es falso, y unas veces lo es y otras no, y así una y otra vez... Y sobre todo los que se han entretenido haciendo argumentos contrapuestos, tú sabes que terminan pensando que son los más sabios y que solo ellos son capaces de entender que no hay nada de nada -ni cosas ni argumentos- que

${ }^{16}$ Reinhard, en un estudio pionero sobre el anacoluto en Platón, lo definía en términos muy parecidos y apuntaba, junto a la caracterización individual del discurso de los personajes, a la información que el empleo del anacoluto como recurso estilístico nos proporciona sobre la propia conciencia lingüística de Platón: «Die Untersuchung von Platons ergibt, dass die sprachliche Form in ihrer Abweichung von der grammatischen Regel fast unbedingt den Veränderungen entspricht, die der Bewusstseinsinhalt des Redenden während des Redens durch der aufsteigende Vorstellungen erfährt. Die sprachliche Form ist also mit anderen Worten der Reflex des Verstellungsverlaufes, der in dem Redenden vor sicht geht. Aus dieser Übereinstimmung folgt eine Bedeutung der Anakoluthe in doppelter oder vielmehr dreifacher Beziehung: einmal sind sie von Wichtigkeit für die psychologische Auffassung der in Betracht kommenden syntaktischen dadurch, dass sie ein geeignetes stilistisches Mittel darbieten, einzelne Personen und Stimmungen zu charakterisieren, oft einen nicht geringen Einblick in die Kunst Platons. Da es sich ferner zeigt, dass sie über ihre Bedeutung für den Einzelfall hinaus in Anwendung und Auswahl alle derselben Fähigkeit und Eigenart des Denkens entspringen, so geben sie indirekt ein Bild von Platons persönlichem Denk- und Empfindungsleben» (Reinhard 1920: 1). Su estudio, que parte de un enfoque psicologista, proporciona sin embargo claves muy importantes para entender la función del anacoluto en la lengua artística platónica y hoy sigue siendo la aproximación más completa a este fenómeno en el conjunto de la producción de Platón. 
sea sano ni firme, sino que todo va y viene arriba y abajo como en el Euripo y nada permanece ningún tiempo en nada.

En el pasaje citado son muchos los aspectos relevantes de cara a la imitación o representación de la inmediatez comunicativa y habrá ocasión de volver sobre algunos de ellos más adelante. En lo que respecta a la falta de planificación sintáctica, es llamativa la interrupción del periodo que ini-

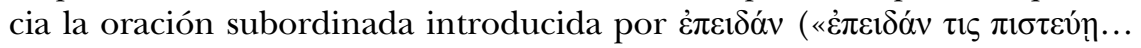

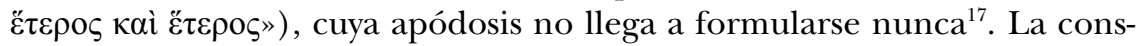
trucción queda inconclusa y Sócrates retoma el discurso en una versión

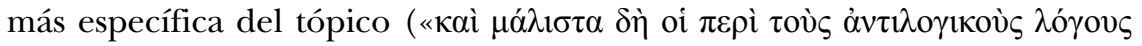
$\left.\delta 1 \alpha \tau \rho i ́ \psi \alpha \nu \tau \varepsilon)^{»}\right)$ que no guarda ya correspondencia sintáctica con la estructura introducida por $\dot{\varepsilon} \pi \varepsilon 1 \delta \alpha ́ v$, sino que figura como un nuevo constituyente sobre el que se predica el contenido informativo que habría sido la apó-

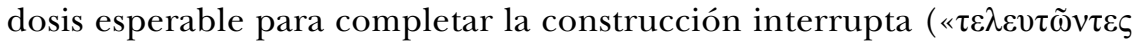

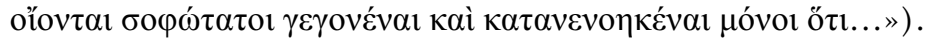

El anacoluto en este pasaje, como en otros, se explica bien como un rasgo de inmediatez comunicativa, producto de la falta de planificación discursiva propia de la oralidad y su dificultad para mantener la coherencia sintáctica durante periodos de gran extensión. Este hecho propio de la lengua hablada es integrado por Platón en la imitación que lleva a cabo en el diálogo literario, y su presencia debe ser interpretada, por tanto, como una pincelada llevada a cabo de forma intencionada para lograr una mejor caracterización estilística. En la misma línea pueden analizarse otros

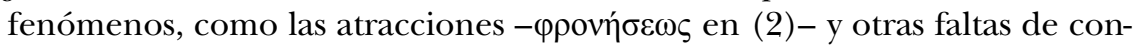

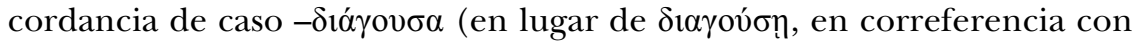

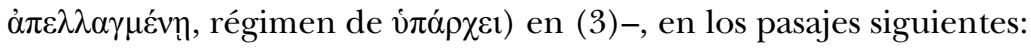

(2) 66d-e: $\dot{\alpha} \lambda \lambda \grave{\alpha} \tau \tilde{\omega}$ őv

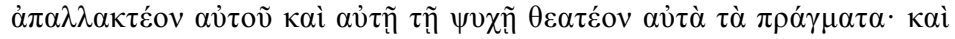

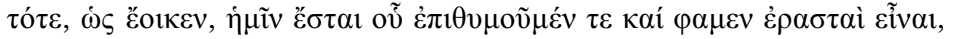

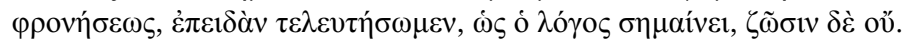

Pero, en realidad, hemos demostrado que, si vamos a saber en algún momento algo con claridad, hay que librarse de él y hay que observar las cosas con el alma; y entonces, según parece, poseeremos lo que deseamos y de lo que decimos que somos amantes, la prudencia, cuando estemos muertos, según indica el argumento, pero no mientras estamos vivos.

${ }_{17}$ Así lo han anotado todos los comentaristas del texto: «The protasis which began at b $6 \dot{\varepsilon} \pi \varepsilon 1 \delta \alpha ́ v$ is forgotten and never resumed» (Burnet 1911: 90); «Da vergisst er, was er vorher gesagt hat, und führt den Gedanken an diesem Beispiel, ohne Rücksicht auf den Anfang,

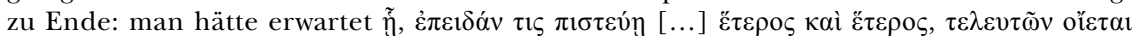

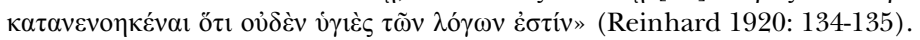




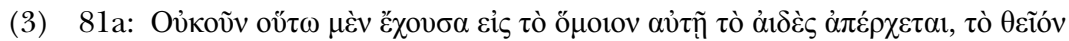

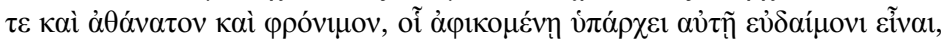

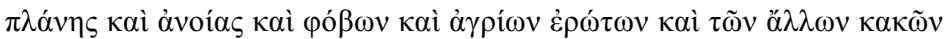

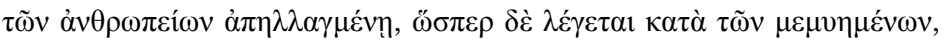

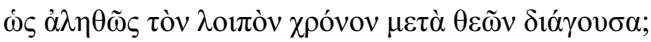

Entonces, ¿es estando así como se dirige a lo invisible semejante a ella, lo divino, inmortal y sabio, a lo que, cuando llegue, le será posible ser feliz, liberada del error, la necedad, los miedos y las pasiones salvajes y todos los demás males de los hombres, como se dice entre los iniciados, para pasar verdaderamente todo el tiempo que le queda entre los dioses?

Es interesante anotar que, además de documentar la recreación de lo oral en lo escrito, esta consideración del anacoluto puede ser también relevante de cara a la crítica del texto platónico, pues los pasajes que contienen fenómenos de este tipo, al ser calificados de desviaciones -cuando no directamente errores- de la norma correcta, son especialmente sensibles durante el proceso de tradición textual, al ser susceptibles de enmiendas o rectificaciones con miras a recuperar la sintacticidad ${ }^{18}$. Su valoración en el seno de un programa estilístico relacionado con la lengua oral y su representación literaria puede proporcionar, por tanto, claves importantes a la hora de decidir entre variantes textuales diversas.

\subsection{Grado de complejidad sintáctica: parataxis e hipotaxis}

Son numerosos los estudios que han concluido que el discurso oral se caracteriza por un predominio de la parataxis como mecanismo de composición, sea en su versión asindética, mediante la mera aposición de elemen-

${ }^{18}$ Cfr. la discusión, en este mismo diálogo, en torno al siguiente pasaje:

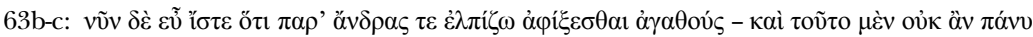

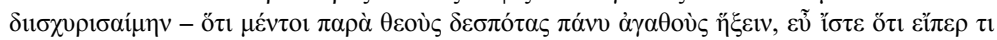

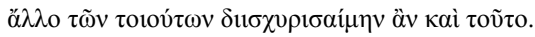

En estas circunstancias, sabed bien que tengo la esperanza de llegar junto a hombres buenos. Y esto no podría afirmarlo con toda seguridad; ahora bien, en lo que respecta a llegar junto a unos dioses que son excelentes patronos, sabed bien que, si puedo afirmar algo con seguridad, es eso.

En el texto que aparece citado, perteneciente a la edición de Burnet, figura después del paréntesis la forma ö $\tau$, atestiguada en un parte de la tradición manuscrita, frente a la forma 七ó, que transmite otra parte de la tradición y avala Juan Estobeo. Burnet (1911: 26) y Verdenius (1958: 199) consideran esta última forma una regularización de la construcción, pero la opción de $\tau$ ó (preferida, entre otros, por Reinhard [1920: 80]) puede interpretarse como una ruptura sintáctica en paralelo a una nueva topicalización discursiva. 
tos, o por procedimiento sindético, mediante las conjunciones de coordinación ${ }^{19}$. Las construcciones hipotácticas, por su parte, encontrarían una mejor acogida en la distancia comunicativa, dado que:

Las oraciones complejas resultantes [sc. de la hipotaxis] presuponen, por su carácter enormemente integrativo, un grado de planificación elevado en la formulación del discurso. El carácter más bien agregativo de la parataxis se amolda bien a la espontaneidad y a las reducidas posibilidades de planificación de la inmediatez comunicativa (Koch y Oesterreicher 2007: 141).

Esta preferencia por la parataxis tiene varios reflejos en la lengua del diálogo platónico. En primer lugar, la progresión sintáctica a través de la coordinación sucesiva de miembros del discurso aflora en pasajes como el siguiente, ubicado en la parte final del Fedón, cuando Sócrates está a punto de beber la cicuta:

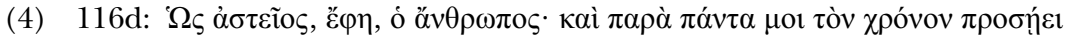

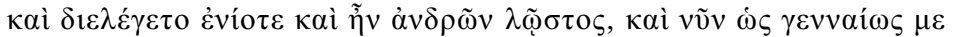

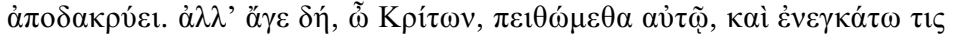

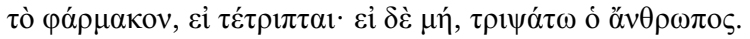

¿Qué agradable es este hombre! Y estaba aquí conmigo todo el tiempo, y me hablaba algunas veces, y era el mejor de los hombres, y ahora con cuánta nobleza llora por mí. Así que vamos ya, Critón, hagámosle caso, y que traiga alguien el veneno, si está ya triturado; y si no, que lo triture el hombre.

Solo en la primera parte de intervención de Sócrates se encadenan cinco unidades sintácticas independientes mediante la conjunción кaí, de forma similar a lo observado y descrito a partir de corpus conversacionales en lenguas modernas. Los distintos elementos -se trata, en todos los casos, de oraciones sintácticamente completas- se van engarzando unos a otros por simple coordinación, evitándose otras combinaciones más complejas. El recurso del polisíndeton, por otro lado, en ningún caso parece encuadrarse en una estrategia retórica de enumeración climática como las que articulan secuencias de miembros crecientes.

Desde otro punto de vista, la tendencia a la parataxis se manifiesta también en procedimientos de organización discursiva basados en la aposición de unidades prosódico-informativas relativamente independientes, que se sitúan unas junto a otras, a menudo sin servirse de otra marca que la autonomía entonativa y la interacción de su propio contenido con el

19 Por ejemplo, Chafe (1982), quien hablaba ya de fragmentación e integración como principios de caracterización prototípica de la lengua hablada y la lengua escrita. O, en la tradición hispánica, los conceptos de sintaxis acumulativa o parcelada (cfr. Narbona Jiménez 1988). 
contexto pragmático para actualizar su función en el discurso. Obsérvese el siguiente pasaje:

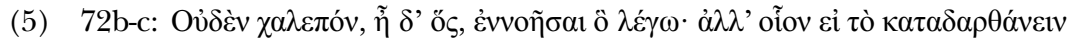

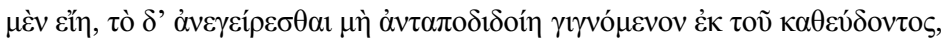

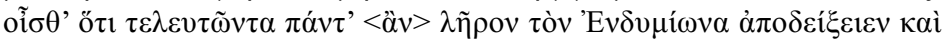

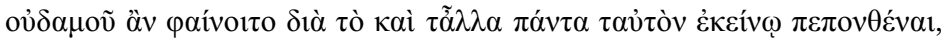
$\kappa \alpha \theta \varepsilon v ́ \delta \varepsilon v$.

Nada difícil -dijo él-de imaginar es lo que digo. Pero, por ejemplo, si existiera el quedarse dormido, pero no se originase en el que duerme el despertarse como contraparte, sabes que al final todo acabaría apuntando a que lo de Endimión fue irrelevante, no sería nada porque le habría pasado lo mismo que todas las demás cosas, quedarse dormido.

El elemento que cierra el texto (5) - $\alpha \theta \theta \varepsilon v ́ \delta \varepsilon ı v-$ se adhiere al resto del enunciado sin procedimientos explícitos de integración sintáctica y posee independencia prosódica. Este tipo de construcciones, no solamente en coda discursiva, sino también en otras posiciones ${ }^{20}$, son relativamente frecuentes en el diálogo platónico y se apoyan en una cierta cualidad de naturaleza entonativa que las conecta directamente con la articulación hablada y, por ende, las sitúa en la esfera de la inmediatez comunicativa. Estas unidades suelen tener, además, un carácter parentético en términos de la estructura discursiva, a menudo ejercen funciones en el seno de la producción discursiva y la formulación, precisando referencias ambiguas o introduciendo reformulaciones de diverso tipo ${ }^{21}$. Obsérvese, por ejemplo, la voluntad de reformulación parafrástica en la intervención del primer

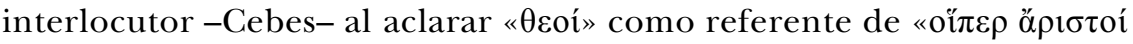

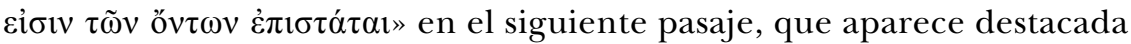
nuevamente a continuación en la respuesta de un segundo interlocutor -Simias- unas líneas más adelante:

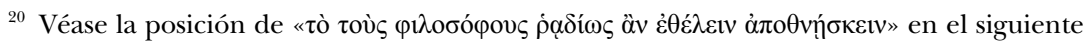
ejemplo, donde se inserta de forma parentética:

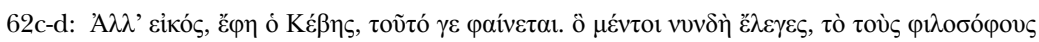

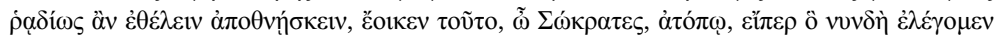

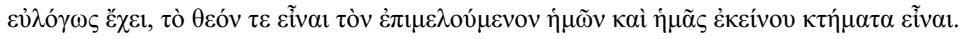

Eso me parece lógico -dijo Cebes-. Pero lo que decías hace un momento, que los filósofos fácilmente querrían morir, eso me parece raro, Sócrates, si lo que decíamos antes tiene algún sentido, que dios es quien está a cargo de nosotros y nosotros somos sus posesiones.

${ }^{21}$ En particular las reformulaciones parafrásticas, cuya relación con la inmediatez comunicativa en el diálogo platónico ha sido objeto de atención en anteriores estudios (cfr. Verano 2017a y 2017b). Sobre el estatus sintáctico de estas aposiciones en griego antiguo cfr. Verano $(2017 \mathrm{c})$. 


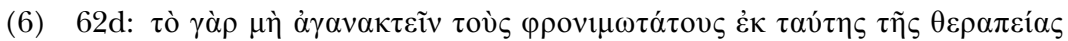

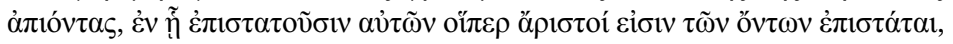

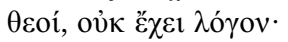

$[\ldots]$

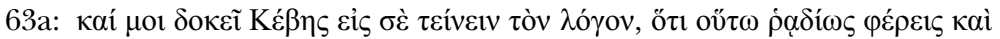

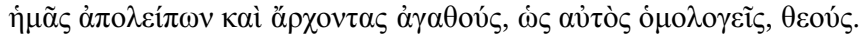

Pues el hecho de que no se irriten los más prudentes de abandonar esta asistencia, en la que los dirigen los mejores dirigentes de cuantos hay, los dioses, no tiene sentido.

$[\ldots]$

Y me parece que Cebes apunta hacia ti su argumento, ya que con tanta facilidad sobrellevas el abandonarnos a nosotros y unos buenos gobernantes, según tú mismo reconoces, los dioses.

Ambos fenómenos -la concatenación paratáctica y la introducción de unidades sintáctica y prosódicamente autónomas en aposición- encuentran su razón ser en las condiciones y características específicas de la lengua oral que Platón imita en sus obras. Pero es necesario apuntar, sin embargo, que la lengua del diálogo platónico se caracteriza también por su intensa subordinación. Incluso en pasajes que pueden considerarse coloquiales por comparecencia de otros rasgos de inmediatez comunicativa, se dan anidamientos hipotácticos que alcanzan un nivel de complejidad que no puede explicarse sino desde las posibilidades de planificación sintáctica que caracterizan las condiciones enunciativas de la distancia comunicativa.

\subsection{Elipsis}

El contexto en el que se da prototípicamente la inmediatez comunicativa, esto es, el intercambio conversacional, propicia, entre otros procedimientos de cohesión discursiva, el de la elipsis, que consiste en la supresión de elementos del enunciado en principio obligatorios desde el punto de vista de su constitución sintáctica, pero que el oyente puede suplir fácilmente $^{22}$. El diálogo platónico hace un uso frecuente de este recurso, espe-

${ }^{22}$ La descripción de la elipsis y sus valores discursivos se remonta a la retórica clásica. Su función en el seno de la cohesión textual fue subrayada ya en el libro de Halliday y Hasan (1976). Koch y Oesterreicher prefieren hablar de «oraciones incompletas» (2007: 125-139), una etiqueta más amplia, que incluiría otros casos además de los que pueden considerarse elipsis stricto sensu. Cfr.: «De acuerdo con Karl Bühler, optamos por restringir el concepto de elipsis a aquellos casos en que realmente -justo en el sentido etimológico propio del término (griego élleipsis 'omisión')- se omita un constituyente oracional, cuya forma material exacta (es decir, no únicamente su sentido, pueda, sin asomo de dudas, ser reconstruida a partir del contexto lingüístico» (Koch y Oesterreicher 2007: 126). 
cialmente entre las intervenciones de diferentes interlocutores, y es muy habitual encontrarlo en respuestas como la que se muestra en los siguientes ejemplos:

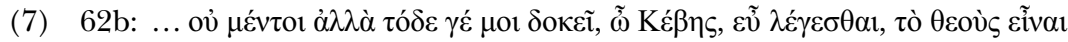

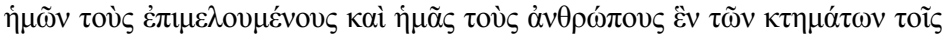

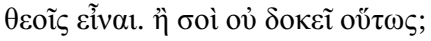

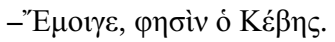

-... Sin embargo, esto me parece a mí, Cebes, que lo dice bien: que los dioses son los que están a cargo de nosotros y que nosotros, los hombres, somos posesiones de los dioses. ¿O no te parece a ti así? -A mí sí-dijo Cebes.

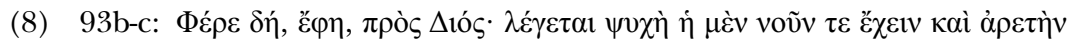

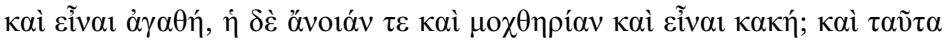
$\dot{\alpha} \lambda \eta \theta \tilde{\omega} \varsigma \lambda \varepsilon \dot{\varepsilon} \gamma \varepsilon \tau \alpha 1 ;$

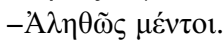

Vamos, ;por Zeus! -dijo-. ¿Se dice que el alma que tiene entendimiento y virtud también es buena y que la que tiene necedad y vicio también es mala? ¿Y esto se dice con veracidad?

-Con veracidad, claro que sí.

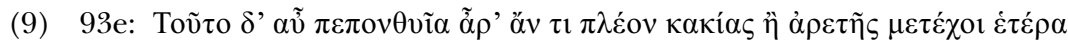

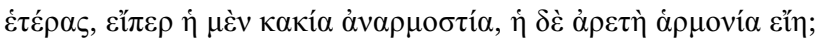

$-\mathrm{O} \delta \dot{\delta} \mathrm{\varepsilon} v \pi \lambda \dot{\varepsilon} \mathrm{ov}$.

-Y a su vez, al estar así, ¿podría participar en algo más del mal o de la virtud un alma que otra, si fuera el mal disarmonía y armonía la virtud?

-En nada más.

En el pasaje resulta muy sencillo enriquecer en el texto (7) la respuesta de Cebes con los elementos necesarios para que la supuesta oración que

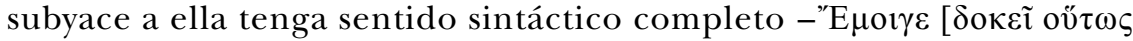

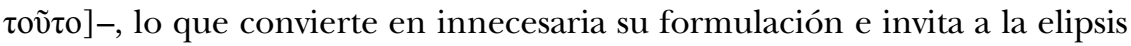
por pura economía lingüística. Algo similar ocurre en (8) y (9) en connivencia con la repetición parcial del enunciado, un aspecto que se tratará más adelante (cfr. 5.5 'figura de simetría').

\subsection{Figura del paréntesis}

Los estudios llevados a cabo sobre corpus coloquiales revelan la importante presencia de unidades discursivas más o menos autónomas que se 
insertan a modo de paréntesis ${ }^{23}$ en la cadena hablada, y mediante las cuales el hablante, interrumpiendo, por así decir, su propia formulación, introduce comentarios, se adelanta a posibles problemas comunicativos, llama la atención del oyente sobre un elemento en particular, etc., de forma similar a como se observa en los ejemplos (10) y (11):

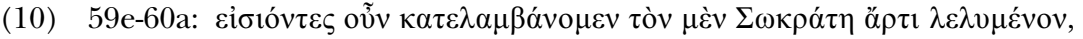

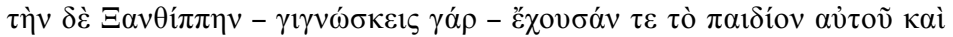
$\pi \alpha \rho \alpha \kappa \alpha \theta \eta \mu \varepsilon ́ v \eta \nu$.

Así pues, al entrar nos encontramos a Sócrates, que acababan de liberarlo, y a Jantipa -tú la conoces- con su hijo, sentada a su lado.

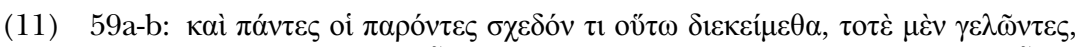

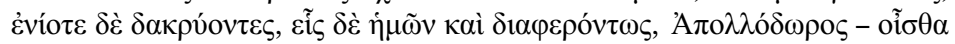

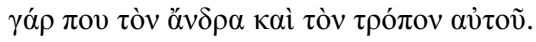

Y todos los que estábamos allí estábamos prácticamente igual, a veces riendo, a veces llorando, especialmente uno de nosotros, Apolodoro - que ya conoces tú al hombre y sabes cómo es.

Donde sendas inserciones parentéticas sirven para aclarar intersubjetivamente la participación del receptor en una pieza particular del conocimiento compartido entre hablante y oyente, convirtiéndose así en un recurso de coherencia interpersonal. Una estrategia similar, pero con el foco en el hablante, se da también a través de una estructura parentética en el ejemplo siguiente:

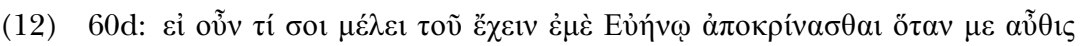

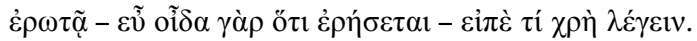

Así pues, si significa algo para ti que yo pueda responderle a Eveno cuando me pregunte de nuevo -pues sé bien que lo hará-, dime qué he de decirle.

Las secuencias de este tipo son auténticos nodos de funciones discursivas, en los que confluyen valores diversos. Son fundamentales para el éxito comunicativo, pues sirven para explorar las relaciones entre hablante y oyente en cuanto a conocimientos, emociones y opiniones compartidas, comprobando así el estado de la base común desde la que se construye el discurso $^{24}$. Desde un punto de vista sintáctico, es relevante su naturaleza

${ }^{23}$ La denominación de figura del paréntesis procede de Blanche-Benveniste (1985). Véase López Serena (2007: 227) para un estudio de la figura tanto en la conversación natural en español contemporáneo como en su recreación en la literatura.

${ }^{24}$ Lo que investigaciones lingüísticas recientes denominan «common ground» (Clark y Brennan 1991). La gestión de este control sobre los conocimientos compartidos entre interlocutores y su mutuo posicionamiento respecto a ideas y opiniones se refleja extraordinariamente bien en muchos contextos de la producción platónica. 
parentética, aislada de la estructura en la que se inserta, como ilustra, en los ejemplos citados, la decisión editorial de notar gráficamente este aislamiento con un signo de puntuación.

\subsection{Figura de simetría}

Bajo el nombre de «figura de simetría» los estudios sobre sintaxis de la lengua oral han reunido toda una serie de usos de la repetición en el discurso, y la imitación platónica de la lengua coloquial da buena cuenta de algunos de ellos ${ }^{25}$. En general, resulta interesante distinguir, en el análisis de las figuras de simetría, los casos en que la repetición se produce entre interlocutores -denominados de repetición dialógica o alo-repetición- de aquellos en que es el propio hablante el que reitera el enunciado o, más frecuentemente, una parte de él -repetición monológica o auto-repetición-, con diversos propósitos en el discurso.

Las repeticiones monológicas como mecanismo de cohesión textual o de énfasis son habituales, como muestra el ejemplo siguiente:

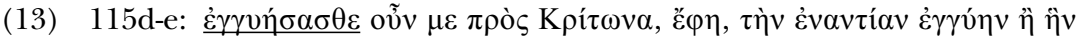

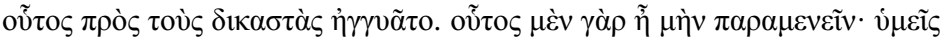

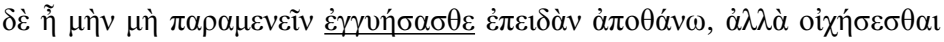

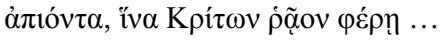

Así pues, avaladme ante Critón - dijo- con un aval contrario al que él me avaló ante los jueces. Pues el suyo era que yo me quedaría. Pero vosotros avalad que no me quedaré cuando muera, sino que os abandonaré y me marcharé, para que a Critón le sea más fácil ...

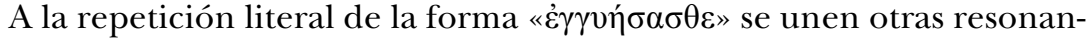

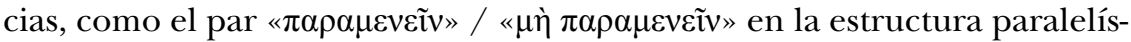
tica con elementos claramente simétricos: «oṽ

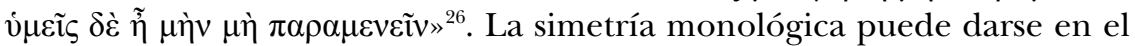

${ }^{25}$ Cfr. Blanche-Benveniste (1985); López Serena (2007: 219-223). Para un estudio sistemático de la repetición en el discurso cfr. Bazzanella (1996 y 2011). No entraremos aquí, por razones de espacio, en precisiones metodológicas de índole formal, relativas a la totalidad o parcialidad de la repetición o a los grados de literalidad y variación (cfr. Verano 2016: 175176): entiéndase que el criterio de aproximación al fenómeno que se maneja en este estudio es abierto, en línea con el desarrollado por las publicaciones citadas en esta nota. En el contexto del diálogo platónico, Verano (2016) analiza las diferentes funciones que actualiza la repetición en La República.

${ }^{26}$ Es importante anotar que, en la figura de simetría monológica, la repetición, sea de materiales léxicos o sintácticos, tiene siempre una función o propósito específico. Caso distinto es el de las repeticiones que se producen en el seno de la llamada iteración léxica (cfr. Koch y Oesterreicher 2007: 149-151), entendida esta como la sobreutilización de un elemento léxico 
seno de un único turno como en el ejemplo (13) o, más adelante, en (15), o a lo largo de más de un turno -en el ejemplo (14) con repetición literal-, y es frecuente la aparición de fórmulas que identifican el segmento como una repetición de materiales anteriores en el discurso, como la secuencia «ö $\varepsilon \rho \rho ~ \alpha ̋ \rho \tau \iota ~ \varepsilon ̌ \lambda \varepsilon \gamma o v »{ }^{27}$ que se aprecia en (15):

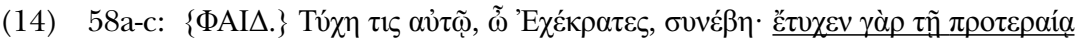

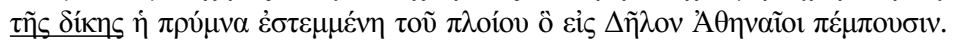
$[\ldots]$

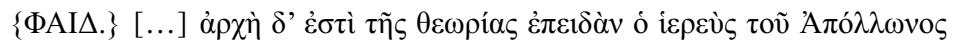

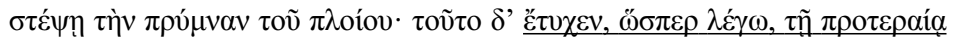

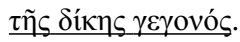

Fedón.- Se dio un azar, Equécrates. Pues se dio el caso de que la víspera del juicio quedó coronada la popa del barco que los atenienses envían a Delos.

$[\ldots]$

FEDón.- ... Es el comienzo de la procesión cuando el sacerdote de Apolo corona la popa del barco. Eso ocurrió casualmente, como digo, la víspera de celebrarse el juicio.

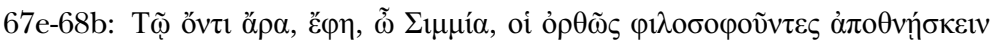

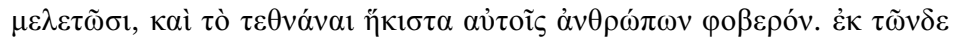

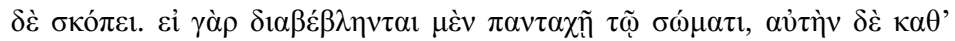

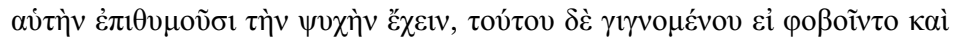

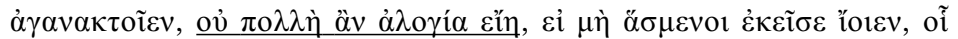

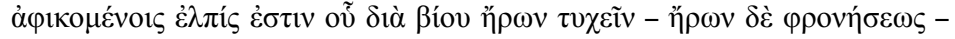

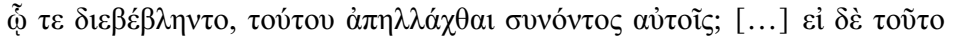

determinado que tiene lugar en el discurso inmediato y que es producto de una escasa variación paradigmática. Este último caso es difícil de encontrar en la lengua de Platón, quien cuida mucho el principio de variatio cuando se ve obligado a repetir en poco espacio palabras o

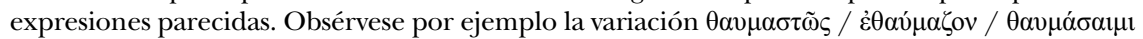
(y $\alpha$ $\tau o ́ \pi \omega \varsigma)$ en el siguiente pasaje:

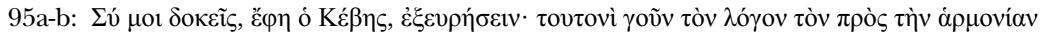

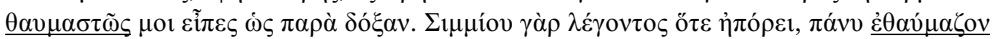

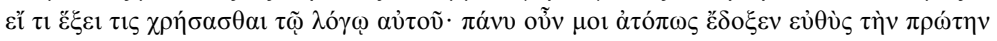
ع̌

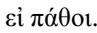

Yo creo que tú lo vas a encontrar -dijo Cebes-. En todo caso este razonamiento sobre la armonía lo has hecho sorprendentemente contra lo que yo esperaba. Porque al exponer Simias sus dudas, yo encontraba realmente sorprendente que alguien pudiera hacer algo con ese argumento. Así que me pareció raro ya que no aguantara ni el primer ataque de tu argumento. Desde luego no me sorprendería que le ocurriera lo mismo también al argumento de Cadmo.

27 Véase Verano (2016: 190). Un estudio específico y exhaustivo sobre estas fórmulas en Platón en Des Places (1929). 


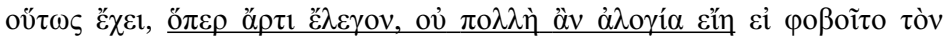

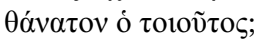

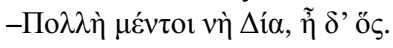

Entonces, en realidad, Simias -dijo- los verdaderos filósofos se ejercitan en morir, y el morir no es nada temible para ellos. Considéralo a partir de esto. $\mathrm{Si}$, efectivamente, están totalmente enemistados con el cuerpo, y desean tener el alma en sí misma y, al suceder esto, si tuvieran miedo y se irritaran, ¿no carecería de toda lógica, si no se fueran gozosos allí donde al llegar tienen la esperanza que amaban tener en vida -pues amaban la prudencia- y librarse de eso con lo que estaban enemistados y que vivía con ellos? [...] Si esto es así, lo que decía hace un momento, ¿no carecería de toda lógica si tal individuo temiera la muerte?

-Pero de toda, ipor Zeus! -dijo él.

Tienen un rendimiento mucho mayor, sin embargo, en el discurso platónico, las llamadas alo-repeticiones o repeticiones dialógicas, es decir, aquellas figuras de simetría que tienen lugar entre las intervenciones de interlocutores distintos. Las funciones que se actualizan en estos casos son, principalmente, las de respuesta afirmativa -por ejemplo, al final del ejemplo (15) anteriormente citado, en compañía de la elipsis (cfr. §5.4) o, a continuación, en (16) y (17) - y las de confirmación o acuerdo respecto al enunciado anterior -(18)-, a veces a la manera de un mero mecanismo de retroalimentación cuya función es prácticamente fática:

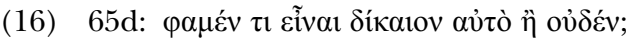

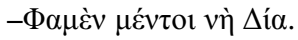

-¿Afirmamos que existe algo justo en sí o nada?

-Lo afirmamos, desde luego, ipor Zeus!

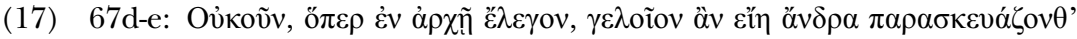

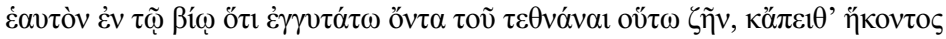

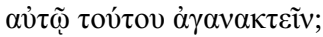

$-\Gamma \varepsilon \lambda$ oĩov $\pi \tilde{\omega} \varsigma$ ' oü;

-¿Entonces, como decía al principio, sería ridículo el hombre que se preparara en vida para estar lo más cerca posible de la muerte, y luego al llegar a este punto se irritara?

-Ridículo, ¿cómo no?

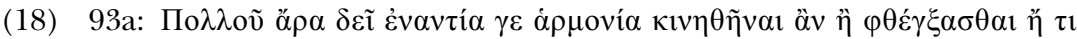

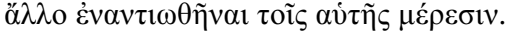

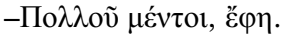

-Entonces no hay ninguna posibilidad de que una armonía contraria pueda moverse o sonar u oponerse de alguna otra forma a sus partes. -Ninguna -dijo. 


\subsection{Figura de enumeración}

La figura denominada de enumeración hace referencia a un fenómeno característico del discurso hablado que consiste en la enunciación sucesiva de elementos que ocupan una misma posición sintáctica. En términos estructurales, la figura se ha definido como una manifestación de la actividad paradigmática en el eje del sintagma, y puede responder a diferentes motivaciones, desde la corrección y reparación formulativa -en línea con la ausencia de planificación propia de la comunicación oral- hasta el énfasis ${ }^{28}$.

Es claro que determinadas instancias de esta figura no se encuentran en la lengua del diálogo platónico - por ejemplo, los abundantes y frecuentes reinicios motivados por errores de formulación de los que difícilmente tiene interés en dar cuenta la estilización literaria-; sin embargo, se dan en determinados pasajes acumulamientos que, si no tienen la misma naturaleza, al menos sí causan un efecto muy parecido, como en (19):

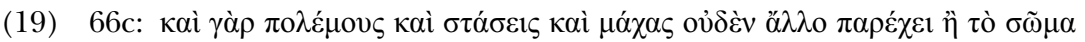

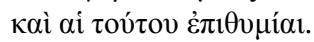

Porque guerras y rebeliones y batallas no las trae ningún otro que el cuerpo y los deseos propios de él.

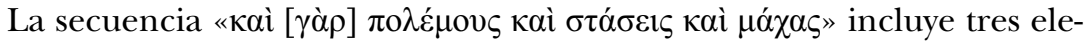
mentos coordinados que ocupan la misma posición sintáctica y tienen, de hecho, naturaleza sinonímica. Responde muy bien al tipo de apilamiento paradigmático que caracteriza la figura de enumeración, al menos en su variante más enfática y, de alguna forma, consigue crear en el seno de la ficción literaria un efecto de búsqueda, como si mediante estas formulaciones sucesivas el hablante, al tiempo que intensifica esta parte del enunciado, estuviera ganando un tiempo necesario para planificar la prosecución del discurso. Los ejemplos de este tipo son elusivos, pero una lectura atenta revela que este tipo de fenómenos forman también parte de la mímesis de la lengua coloquial que se lleva a cabo en el diálogo platónico ${ }^{29}$.

${ }^{28}$ Cfr. Blanche-Benveniste (1985). López Serena aplica la denominación a «todos los casos de apilamiento paradigmático en el eje sintagmático debidos a la yuxtaposición de cualesquiera elementos (palabras, partes de palabras o sintagmas completos) que ocupen una misma posición sintáctica» (2007: 223).

${ }^{29}$ Estas enumeraciones se solapan con otros fenómenos propios de la inmediatez comunicativa. En determinadas ocasiones resulta difícil distinguir contextos de este tipo de las llamadas aposiciones parafrásticas, como las estudiadas en epígrafes anteriores (cfr. \$5.2). Desde un punto de vista prototípico, existe en las segundas una clara voluntad reformulativa de la que carecen las primeras, pero esta distinción, manifiesta en muchos casos, pierde definición otras veces, y en la imitación platónica, donde no es poca la ambigüedad que rodea la interpretación de muchos de estos elementos, se vuelve una ardua tarea identificar sus valores. 


\section{Conclusiones}

En las páginas finales del Fedón, Sócrates conmina a sus amigos en su última hora a no dejar de vivir «siguiendo las huellas de lo que hemos con-

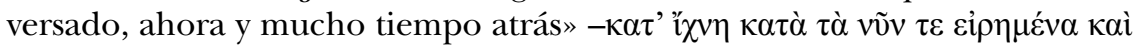

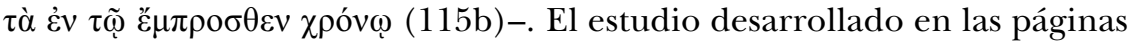
anteriores ha intentado, desde una perspectiva diferente, explorar esas mismas huellas, con objeto de encontrar en ellas el rastro de la conversación que este diálogo literario y filosófico imita y reproduce.

El análisis de Fedón aquí expuesto, deudor de contribuciones anteriores tanto en el ámbito de la lingüística contemporánea como en el de la estilística platónica tradicional, ha mostrado una serie de fenómenos que pueden considerarse característicos de la sintaxis propia de la lengua oral y cuya presencia se explica desde la mímesis conversacional que lleva a cabo Platón en sus obras. Las construcciones y figuras que se han recogido y estudiado aquí -anacolutos, encadenamientos paratácticos, elipsis, repeticiones, inserciones parentéticas, enumeraciones, etc.- forman parte de una misma constelación estilística que articula toda una serie de rasgos diversos a través de los cuales la inmediatez comunicativa se hace manifiesta en las intervenciones de los personajes de los diálogos, haciendo así resonar sus voces en las páginas escritas. El repertorio de fenómenos descritos no es en modo alguno exhaustivo o cerrado, sino una primera propuesta que debe ser puesta a prueba y verse completada con análisis futuros llevados a cabo sobre el mismo corpus platónico y sobre otras obras literarias griegas que puedan albergar marcas de oralidad.

Al mismo tiempo, esta contribución al estudio de la lengua de Platón pretende serlo también al de una tradición discursiva que nace en la obra del filósofo ateniense y tiene continuidad en el diálogo filosófico que crece y se desarrolla durante toda la Antigüedad hasta la Edad Media y el Renacimiento. Las relaciones entre inmediatez y distancia comunicativas que se dan en el seno de las distintas propuestas artísticas desde las que asumen los retos de este género literario cada uno de los autores y épocas que lo cultivan deben ser dilucidadas, con objeto de esbozar un panorama completo de la evolución de esta forma que ha sido vehículo de expresión privilegiado de la ciencia y la filosofía durante siglos. Y en el punto de partida de esta tradición persiste la figura de Platón, de cuya sensibilidad a la hora de entreverar lo escrito y lo oral ha intentado ser testigo este trabajo. 


\section{BIBLIOGRAFIA}

Bazzanella, Carla (1996): Repetition in Dialogue, Tübingen: Niemeyer.

- (2011): «Redundancy, repetition, and intensity in discourse», Language Sciences $33 / 2,243-254$.

Blanche-Benveniste, Claire (1985): «Las regularidades configurativas en el discurso francés hablado. Consideraciones lingüísticas y sociolingüísticas». En F. Rodríguez-Izquierdo (ed.), Sociolingüistica Andaluza 3. El discurso sociolingüistico, Sevilla: Universidad de Sevilla, 19-30.

BRANDWoOd, Leonard (1990): The Chronology of Plato's Dialogues, Cambridge: Cambridge University Press.

Burnet, John (1911): Plato, Phaedo, Oxford: Oxford University Press.

Campbell, Lewis (1867): The Sophistes and Politicus of Plato, Oxford: Clarendon Press.

Chafe, William L. (1982): «Integration and involvement in speaking, writing, and oral literature». En D. Tannen (ed.), Spoken and Written Language, Norwood: ABLEX Pub., 35-53.

Clark, Herbert H. y Susan E. Brennan (1991): «Grounding in Communication». En L. B. Resnick, J. M. Levine y S. D. Teasley (eds.), Perspectives on Socially Shared Cognition. Washington, DC: American Psychology Association.

De Bustos Tovar, José Jesús (2001): «De la oralidad a la escritura en la transición de la Edad Media al Renacimiento: la textualización del diálogo conversacional», Criticón 81-82, 191-206.

Del Rey Quesada, Santiago (2015): Diálogo y traducción: los Coloquios erasmianos en la Castilla del siglo XVI, Tübingen: Narr Verlag.

- (2013): «El diálogo entre enunciación y género: una perspectiva desde la hispanística», Romanistisches Jahrbuch 64, 217-247.

- (2011): «Oralidad y escrituralidad en el diálogo literario: el caso de los Coloquios de Erasmo». En J. J. de Bustos Tovar et al. (eds.), Sintaxis y análisis del discurso hablado en español: homenaje a Antonio Narbona, Sevilla: Universidad de Sevilla, II, 695-711.

Des Places, Édouard (1929): Une formule platonicienne de récurrence, Paris: Les Belles Lettres.

DíAz Tejera, Alberto (1961): «Ensayo de un método lingüístico para la cronología de Platón», Emerita. Revista de Lingüistica y Filología Clásica 29, 241-286.

Dittenberger, Wilhelm (1881): «Sparchliche Kriterien für die Chronologie der platonischen Dialoge», Hermes 16, 321-345.

DuHoux, Yves (1997): «Grec écrit et grec parlé: un étude contrastive des particules aux V-IV s.». En A. Rijksbaron (ed.), New Approaches to Greek Particles, Ámsterdam: J. C. Gieben, 15-48.

EAsterling, Patricia E. y Bernard M. W. Knox (eds.) (1985): The Cambridge History of Classical Literature, Cambridge: Cambridge University Press. 
Gallop, David (1975): Plato, Phaedo, Oxford: Oxford University Press.

García Gual, Carlos (1986): «Fedón». En Diálogos III: Fedón, Banquete, Fedro, Madrid: Gredos.

Halliday, Michael A. K. y Ruqaiya Hasan (1976): Cohesion in English, London: Longman.

Koch, Peter y Wulf OesterReICHer (2007): Lengua hablada en la Romania: español, francés, italiano, Madrid: Gredos.

LóPEz SERENA, Araceli (2008): «El sesgo escriptista en la historia de la reflexión sobre el lenguaje y en la ciencia lingüística contemporánea: la escritura como instrumento conceptual y filtro analítico falaz», Lynx: Panorámica de estudios lingüisticos 7, 135-153.

- (2006): «La impronta estructuralista de las escuelas de Tubinga y Friburgo. Presente, pasado y futuro de la lingüística de variedades alemana». En Caminos Actuales de la Historiografía Lingüistica. Actas del V Congreso Internacional de la SEHL, Murcia: Universidad de Murcia, 995-1007.

- (2007): Oralidad y escrituralidad en la recreación literaria del español coloquial, Madrid: Gredos.

- y Margarita Borreguero Zuloaga (2010): «Los marcadores del discurso y la variación lengua hablada vs. lengua escrita». En Ó. Loureda Lamas y E. Acín Villa (eds.), Los estudios sobre marcadores del discurso en español, hoy, Madrid: Arco/Libros.

LUTOSLAWSKI, Wincenty (1897): The origin and growth of Plato's Logic with an account of Plato's style and the chronology of his writings, London: Longman.

NARBona JimÉNEZ, Antonio (1988): «Sintaxis coloquial: problemas y métodos», LEA, X/1, 81-106.

Ramos Jurado, Enrique Á. (2002): Platón, Apología de Sócrates - Fedón, Madrid: Consejo Superior de Investigaciones Científicas.

ReInHARD, Luise (1920): Die Anakoluthe bei Platon, Berlin: Weidmann.

RITTER, Constantin (1888): Untersuchungen über Platon, Stuttgart: W. Kohlhammer.

Sedley, David y Alex Long (2010): Plato. Phaedo \& Meno, Cambridge: Cambridge University Press.

TARRANT, Dorothy (1946): «Imagery in Plato's Republic», The Classical Quarterly 40/1-2, 27-34.

— (1948): «Style and thought in Plato's Dialogues», The Classical Quarterly 42/1-2, 28-34.

- (1951): «Plato's use of quotations and other illustrative material», The Classical Quarterly N.s. 1/1-2, 59-67.

ThesLefF, Holger (1954): Studies on intensification in Early and Classical Greek, Helsinki: Societas Scientiarum Fennica.

- (1967): Studies in the styles of Plato, Helsinki: Suomalaisen Kirjallisuuden Kirjapaino.

- (1982): Studies in Platonic chronology, Helsinki: Societas Scientiarum Fennica.

VERANO, Rodrigo (2016): «Funciones discursivas de la repetición en el diálogo platónico», Minerva. Revista de Filología Clásica 29, 171-192.

- (2017a): «La imitación platónica de la lengua hablada: algunos rasgos de la oralidad en La República». En J. de la Villa et al. (eds.), Conuentus Classicorum. 
Temas y Formas del Mundo Clásico. Temes y Formes del Món Clàssic, Madrid: Sociedad Española de Estudios Clásicos, 389-396.

— (2017b): «Oralidad y escritura en el diálogo platónico», Synthesis 24/2, 39-58.

- (2017c): «Linguistic paraphrase in Platonic Dialogue: A first approach». En F. Logozzo y P. Pocetti (eds.), Ancient Greek Linguistics: New Perspectives, Insights, and Approaches, Berlin; Boston: De Gruyter, 475-488.

Verdenius, Willem J. (1958): «Notes on Plato's Phaedo», Mnemosyne 11, 193-243. 